\title{
Nanotecnologia Aplicada Ao Cimento De Ionômero De Vidro Convencional: Avaliação Da Reação de Presa e Perda do Brilho.
}

\section{Caroline Braido*; Kelly Maria Silva Moreira; Isaac Jordão de Souza Araújo; Priscila Alves Giovani; Orisson Ponce Gomes; Paulo Noronha Lisboa- Filho; Regina Maria Puppin-Rontani; Kamila Rosamilia Kantovitz.}

\section{Resumo}

O dióxido de titânio (TiO2) tem sido sugerido como material promissor em diversas aplicações, incluindo nos materiais restauradores odontológicos. Assim, o presente estudo in vitro investigará a influência da incorporação de diferentes concentrações de nanotubos de TiO2 nas propriedades físicas do cimento de ionômero de vidro (CIV) convencional.

\section{Palavras-chave:}

Cimentos de lonômero de Vidro; Nanotecnologia; Propriedades Físicas; Titânio.

\section{Introdução}

A associação de nanotubos de $\mathrm{TiO}_{2}$ ao $\mathrm{CIV}$ tem mostrado resultados positivos frente as limitações mecânicas desse material. Entretanto, a influência desta nanotecnologia nas propriedades físicas (reação de presa e perda de brilho) do CIV ainda não estão bem estabelecidas. Assim, o objetivo do estudo in vitro é avaliar a influência da incorporação de diferentes concentrações de nanotubos ( $0 \%, 3 \% ; 5 \% ; 7 \%$ em peso), sintetizados pelo método alcalino $(20 \mathrm{~nm})$ incorporados ao Ketac Molar EasyMix quanto ao tempo de geleificação inicial e final e perda de brilho por meio de agulhas de Gillmore em intervalos de $30 \mathrm{~s}$.

\section{Resultados e Discussão}

Os valores de médias e desvio padrão (DP) em segundos (s) dos tempos de presa inicial, final e perda de brilho apresentam-se na Tabela 1. KM contendo $7 \%$ de $\mathrm{TiO}_{2}$ exibiu o valor mais elevado de tempo de presa inicial diferindo estatisticamente dos grupos controle (KM) e do grupo contendo $3 \%$ de TiO2 $(p<0,01)$ (Tabela 1). Este aumento no tempo de presa inicial se deve a redução na proporção do pó do ionômero convencional causado pela diluição das nanopartículas de $\mathrm{TiO}_{2}$, isto pode ser observado no estudo de Prentice LH, et al. (2006). Ana ID, et al. (2003), analisou que a adição de partículas (vidros bioativos) ao CIVs modificados por resina também resultou no prolongamento do tempo de presa conforme o aumento da concentração das partículas.

Garcia-Contreras R, et al.(2015) cita que concentrações de $3 \%$ e $5 \%$ de nanopartículas de $\mathrm{TiO} 2$ aumenta a resistência à flexão, à compressão e reduz a atividade microbiana. Concluindo que concentrações mais baixas mantêm o tempo de presa inicial semelhante ao CIV convencional e proporciona melhorias nas atividades mecânicas deste material. Para as variáveis tempo de presa final e perda de brilho não houve diferença significativa entre os grupos com e sem a presença de nanotubos de $\mathrm{TiO}_{2}(p \geq 0,05)$ (Tabela 1). Conforme descrito na literatura básica de Anusavice (2005), a perda do brilho ocorre durante a reação de geleificação, e indica uma redução na presença de poliácidos disponíveis para se ligar as partículas de vidro, isso está relacionado diretamente com os tempos de trabalho e presa do material, uma vez que não houve no presente estudo diferença no tempo presa final os resultados encontrados para perda brilho estão de acordo com o esperado.
Tabela 1. Média e desvio padrão do tempo de presa inicial, tempo de presa final e perda de brilho em segundos (s).

\begin{tabular}{lccc}
\hline $\begin{array}{c}\text { Grupos } \\
\text { experimentais }\end{array}$ & $\begin{array}{c}\text { Tempo de presa } \\
\text { inicial }\end{array}$ & $\begin{array}{c}\text { Tempo de presa } \\
\text { final }\end{array}$ & $\begin{array}{c}\text { Perda do } \\
\text { brilho }\end{array}$ \\
\hline $\mathrm{KM}($ controle) & $334,25(7,47) \mathrm{B}$ & $400,83(12,19) \mathrm{A}$ & $322,25(7,48) \mathrm{A}$ \\
$\mathrm{KM}+3 \% \mathrm{TiO}_{2}$ & $331,75(7,23) \mathrm{B}$ & $394,5(11,61) \mathrm{A}$ & $322,25(7,48) \mathrm{A}$ \\
$\mathrm{KM}+5 \% \mathrm{TiO}_{2}$ & $335,75(10,26) \mathrm{AB}$ & $395(11,10) \mathrm{A}$ & $319,91(7,06) \mathrm{A}$ \\
$\mathrm{KM}+7 \% \mathrm{TiO}_{2}$ & $344,16(6,84) \mathrm{A}$ & $400,16(7,46) \mathrm{A}$ & $326,41(7,58) \mathrm{A}$ \\
\hline
\end{tabular}

Os dados foram submetidos aos testes de Shipiro-Wilks (normalidade de distribuição), ANOVA e Tukey $(\alpha=0,05)$.

\section{Conclusões}

Pode-se concluir que a incorporação na concentração de $7 \%$ de $\mathrm{TiO}_{2}$ ao $\mathrm{CIV}$ alterou a velocidade de presa inicial do cimento, entretanto concentrações mais baixas mantem o tempo de presa inicial do produto sem a adição de nanotubos de $\mathrm{TiO}_{2}$. A velocidade da presa final e a perda de brilho não se alteram pela incorporação da nanotecnologia.

\section{Agradecimentos}

À minha orientadora, Profa. Dra. Kamila R. Kantovitz pelo conhecimento e oportunidade de trabalhar neste projeto. A Kelly M. S. Moreira e Isaac J. de Souza Araújo pela contribuição e ajuda neste estudo. Ao Departamento de Materiais Dentários da FOP- UNICAMP que cedeu gentilmente para realização deste experimento a sala de controle de temperatura e umidade e as agulhas Gillmore. Ao Prof. Dr. Paulo Noronha Lisboa-Filho (UNESP/Bauru) pela parceria em ceder os nanotubos de $\mathrm{TiO}_{2}$. Ao PIBIC pela concessão da bolsa de estudo para realização deste trabalho, e a FAPESP (16/13786-0) pelo auxílio na compra dos materiais.

1. Ana ID, Matsuya S, Ohta M, Ishikawa K. Effects of added bioactive glass on the setting and mechanical properties of resin-modified glass ionomer cement. Biomaterials 24 (2003) 3061-3067.

2. Garcia-Contrras R, Scougall-Vilchis J, Contreras-Bulnes R, Sakagami H, Morales- Luckie RA, Nakajima H. Mechanical, antibacterial and bond strength properties of nano-titanium-enriched glass ionomer cement. J Appl Oral Sci. 2015;23(3):321-8

3. Prentice LH, Tyas MJ, Burrow MF. The effect of ytterbium fluoride and barium sulphate nanoparticles on the reactivity and strength of a glass-ionomer cement. Dental Materials. 22 (2006) 746-751.

4. Anusavice KJ \& Phillips - Materiais Dentários, 11. Ed; Elsevier LTDA, 2005. 